\title{
Influence Parameters of Storage on Process of Formation the Histamine in Fish and Fish Products
}

\author{
Yakov Verkhivker ${ }^{1, *}$, Ella Altman ${ }^{2}$ \\ ${ }^{1}$ Department of Food, Odessa National Academy of Food Technologies, Odessa, Ukraine \\ ${ }^{2}$ Department of Cooling, Odessa National Academy of Food Technologies, Odessa, Ukraine
}

\section{Email address:}

Yaverkhivker@gmail.com (Y. Verkhivker),Ellaa@ukr.net (E. Altman)

${ }^{*}$ Corresponding author

\section{To cite this article:}

Yakov Verkhivker, Ella Altman. Influence Parameters of Storage on Process of Formation the Histamine in Fish and Fish Products. Journal of Water Resources and Ocean Science. Vol. 7, No. 1, 2018, pp. 10-14. doi: 10.11648/j.wros.20180701.12

Received: December 11, 2017; Accepted: January 1, 2018; Published: January 17, 2018

\begin{abstract}
Results over of researches of maintenance of histamine are brought in fish. As materials for researches products are used from the different points of fishing-out of fish. For realization of researches used sensory, chemical and biological methods. The level of histamine has been examined in frozen fish and canned fish. The dynamics of histamine change that has been traced depends on the temperature of storage, technological parameters.
\end{abstract}

Keywords: Histamine, Sensory, Chemical Photocolorimetry Methods, Biogenic Amines, Blanching

\section{Introduction}

Fish industry plays a considerable role providing of population food, and industries of national economy - by raw material, and also in the recreation of natural resources and increase of employment of population. A physiologically reasonable annual requirement in fish and fish products is 20 kilogram per capita. The aim of researches is an improvement of methodology of estimation of quality of the canned foods from aquatic lives by clarification of parameters of estimation of this products, including parameters of her safety.

The degree of accumulation of histamine in fish products depends on the amount of histidine in fish tissues, the presence of the enzyme histidine-decarboxylase, the conditions for the harvesting of raw materials, storage of raw materials and finished products, the types of processing of raw materials and other parameters. The mass fraction of histidine varies depending on the type of fish, age and other factors. As the fish grows, the amount of histidine increases, especially in the dark musculature that is characteristic of fish of some of the following families. With the participation of the decarboxylase enzyme, the decarboxylation reaction of other amino acids of fish meat proceeds, forming histamine and other biogenic amines. Histamine is not inactivated by normal heat treatment. In addition, fish can contain a toxic level of histamine without showing any organoleptic parameters characteristic of spoilage. [1] Accumulation of histamine in food products under certain conditions can cause poisoning. Given the dangerous effect of products with a high content of histamine on the human body, many countries have imposed restrictions on its content. In accordance with Commission Regulation (EC) No 2074/2005 [2] limits histamine tolerance limits re regulated as a microbiological criterion, especially for fish of the families Scomridae, Clupeidae, Engraulidae, Coryphaenidae, Pomatomidae, Scomberesocidae, in quantities from 100 to $200 \mathrm{mg} / \mathrm{kg}$ and from 200 to $400 \mathrm{mg} / \mathrm{kg}$ for products from the same fish species subjected to enzymatic maturation in the brine. In accordance with [3] in the Russian Federation, the histamine remote control is determined for salmon, herring, tuna and mackerel in quantities up to $100 \mathrm{mg} / \mathrm{kg}$, in Ukraine in accordance with [4] the remote control is installed for all species of fish in an amount up to $100 \mathrm{mg} / \mathrm{kg}$. The maximum allowable concentration of histamine in the USA and Canada is allowed in raw materials up to $50 \mathrm{mg} / \mathrm{kg}$ (manufacturers of canned fish control the raw materials at a rate of $5-15 \mathrm{mg} / \mathrm{kg}$ histamine), in Australia - up to $100 \mathrm{mg} /$ $\mathrm{kg}$, in Sweden - up to $100 \mathrm{mg} / \mathrm{kg}$ in fresh fish and not more than $200 \mathrm{mg} / \mathrm{kg}$ in salted fish. In Ukraine, the histamine 
remote control in fish raw materials corresponds to the remote control in ready-made canned fish. The paradox of the lack of toxicity of preparations of pure histamine taken exogenously, and the apparent toxicity of much smaller doses of histamine in spoiled canned fish canned. are explained by the possible presence of substances in the excavated fish that enhance the toxicity of histamine. It is possible that such "potentiating" substances present in food products may be trimethylamine, agmatine, putrescine, cadaverine, anserine, spermine and spermidine [5]. According to the data of the scientists [6], the indicator of the quality of fish is the content of putrescine, cadaverine, histamine, as well as trace amounts of spermidine and spermine. Ritchie and Mackie [7] note a significant accumulation of histamine, cadaverine and putrescine in mackerel and herring in the storage of fish. A group of Japanese scientists studied the content of amines such as putrescine, cadaverine, tyramine, tryptamine, spermidine, spermine in fresh fish. It was noted that the content of spermine decreases during storage, spermidine remains constant, and putrescine, cadaverine and tyramine significantly increase.

In order to study the stability of histamine during the storage of sterilized canned food, Russian experts performed an experiment under conditions of artificial aging at a temperature of $37^{\circ} \mathrm{C}$. Histamine was determined by the photocolor-imetry method. The objects were canned from tuna, pink salmon, Atlantic mac-kerel, domestic and foreign manufacturers. In the overseas production of tuna and mackerel, the Atlantic did not the mass fraction of histamine. In canned tuna, blanched in oil, Russian production for four months, the value of the indicator increased by 1.5 times, and in natural canned from pink salmon - seven times.

\section{Materials and Methods of the Study}

\subsection{Materials of the Study}

The objects of research conducted by the authors of this article were sardinella moraine, canned natural with added oil, canned products fried in tomato sauce, canned natural in its own juice. The determination of the mass fraction of histamine was carried out by the photocolorimetry method. Sampling and preparation for testing were carried out in accordance with the requirements of regulatory documents.

More than 2,000 samples of frozen fish of various manufacturers which were provided for testing for the level of histamine. To track and analyze the histamine content in frozen fish, the authors selected two species of fish: mackerel and sardinella, the histamine content of which is higher than in other test fish frozen samples (Tables 1,2).

Table 1. Level of histamine content in mackerel frozen, imported to Ukraine.

\begin{tabular}{|c|c|c|c|c|}
\hline \multirow{2}{*}{ Manufacturer of frozen mackerel, declared by the customer } & \multicolumn{4}{|c|}{ Mass fraction of histamine ( $\mathrm{mg} / \mathrm{kg}$ ) in frozen mackerel (year) } \\
\hline & 2008 & 2009 & 2010 & 2011 \\
\hline Mauritania & $38-40$ & - & - & - \\
\hline Scotland & $38-57$ & $12-55$ & $34-67$ & - \\
\hline Morocco & $43-66$ & $68-92$ & - & $25-69$ \\
\hline Norway & $34-67$ & $51-92$ & - & 22 \\
\hline Iceland & $31-56$ & $21-22$ & $28-56$ & $48-80$ \\
\hline Ireland & $30-31$ & - & - & $42-45$ \\
\hline Netherlands & $38-42$ & - & $38-42$ & - \\
\hline New Zealand & $30-60$ & $15-95$ & $30-60$ & $25-96$ \\
\hline Russia & $28-60$ & - & - & - \\
\hline United States of America & - & $15-17$ & - & - \\
\hline United Kingdom & - & $23-87$ & - & $27-38$ \\
\hline
\end{tabular}

Table 2. The level of histamine content in sardinella frozen, imported into Ukraine.

\begin{tabular}{|c|c|c|c|c|}
\hline \multirow{2}{*}{ Producer of sardinella frost } & \multicolumn{4}{|c|}{ Mass fraction of histamine (mg / kg) in frozen sardinella (year) } \\
\hline & 2008 & 2009 & 2010 & 2011 \\
\hline Mauritania & $21-71$ & - & $40-55$ & 39 - more than $400^{*}$ \\
\hline Scotland & $40-42$ & - & - & - \\
\hline Morocco & $64-68$ & - & $36-44$ & $39-98$ \\
\hline Russia & $39-46$ & - & $21-42$ & - \\
\hline United States of America & - & $81-91$ & - & - \\
\hline Panama & - & - & $15-45$ & - \\
\hline
\end{tabular}

*Of the 62 samples of frozen sardinella from Mauritania, the content of histamine more than $100 \mathrm{mg} / \mathrm{kg}$ in $12 \mathrm{samples}(14.6 \%)$ and more than $400 \mathrm{mg} / \mathrm{kg}$ in 15 samples $(18.3 \%)$.

From Table. 1 and 2 it can be seen that the problem of histamine content in raw materials entering Ukraine is quite relevant.

\subsection{Methods of the Study}

At implementation of researches were conducted sensory, 
chemical and bacteriological.

\subsubsection{Sensory Researches}

In practice, for the estimation of consumer properties of fish and fish commodities mostly apply sensory methods. These methods allow quickly and reliably enough to estimate quality of product.

For providing of exact enough results of estimation good illumination is needed - natural daily. Examination of product at lamplight is admitted to the places, wherever climatic terms allow to use natural daily illumination. In this case for lamplight apply fluorescent lamps with a spectrum near to the natural spectrum. A temperature of product must be from 18 to $20^{\circ} \mathrm{C}$ (except the especially specified temperature), it is necessary also to provide absence of draughts, extraneous smells. The basic sensory indexes is: a color of product, a smell of product; a taste of product.

Color of product, his original appearance

The estimation of dermic-scaly cover is conducted: transparency and color of mucus, color of skin, mechanical damages of scale of fish.

For fresh fish mucus is transparent and colorless. With reduction of degree of freshness mucus becomes cloudy and painted, depending on the type of fish and the stages of loss of freshness, in whitish, milk, cream, yellow, grey-bloody and other colors. The natural silvery color of skin grows dim, spots and stripes (for determination of color of skin mucus is carefully washed off) appear.

With the loss of freshness the belly of fish loses the pearl white coloring with an easy pink tint, acquires an intensivelypink, red and even brown color or appears

\section{Determination of consistency}

The consistency of fish, fish and other foods of sea determine at the easy compression of product by fingers.

Consistency of all frozen foods (except the frozen surimi) is determined after their unfreezing to the temperature in the layer of body of fish or block of product from 0 to $5^{\circ} \mathrm{C}$. For determination of consistency of meat of fish-raw do a slanting cut by a sharp knife in the most incrassate part of fish. Consistency dense, if at pressing on the edges of cut meat is strongly springy and tracks desiring poorly, tracks of deformation disappear slowly, but fully; consistency soft, if meat is not springy, is marked easy displacement layers in relation to each other, the appearing here deepening does not disappear fully.

Determination of smell

The smell of living fish and living invertebrates is determined on their surface, and for fish also and in branchiest. For determination of smell of fish-raw the piece of meat, whereupon smell the pounded fabric. For the receipt of additional information fish is cut by a sharp knife on the middle of back from a tail flipper to the middle of head, bare a backbone, after $\mathrm{T}$ adherent to him muscular fabrics along a backbone. For fresh fish a peculiar to her smell is clearly expressed. For different fishes it is a smell of algae, ozone or fresh turned-blown off cucumber. With worsening of quality meat of fish acquires a characteristic smell gradually

\section{Determination of taste}

The taste of the fish and other foods, intended to the use without further culinary treatment determine at chewing (simultaneously with determination of smell). Taste of the foods exposed to cooling or freezing, determine simultaneously with determination of smell after the preliminary taking of tests to the temperature not below $18^{\circ}$ with and exposed to heat treatment after the preliminary cooling to $30^{\circ} \mathrm{C}$.

\subsubsection{Chemical Methods of Researches}

As chemical methods of researches applied:

Method of high-efficiency liquid chromatography

Method of quantitative determination of histamine by means of RIDASCREEN

Colorimetry method

The method of determination of mass concentration of concrete substances in fish and marine invertebrates consists in the chromatography division of components a method high-efficiency liquid to the chromatography with further registration of chromatograms (measuring of intensity of fluorescence derivative, got at co-operation, for example, of histamine with the fluorescent detector.

In basis of procedure of method of quantitative determination of histamine by means of test system RIDASCREEN co-operating of antigens lies with antibodies. Plane-table entering in the complement of set of RIDASCREEN ${ }^{\circledR}$ Histamine 96, Investigated standards and solution, containing antibodies to the acidulated histamine measured out in the small holes of plane-table. In the process of colorimetry method, the chemical co-operating with a chromogen, in that the enzymic fragment of molecule of small hole constrained on a surface, comes forward as a catalyst, the painted foods of reaction appear. Through set time of development of the colored reaction as a result of that a colorless chromogen is painted in a blue color, to the small holes stop reagent is added, here the blue color of solution changes on yellow. The absorbency in small holes, measured on a spectrophotometer at $450 \mathrm{~nm}$, is inversely proportional to the concentration of histamine in the investigated standards.

\subsubsection{Microbiological Methods of Analysis}

Fish can food must be industrially-sterile. Industrial sterility of can food means absence in foods of microorganisms, able to develop at the temperatures of storage, can food set for this kind, and absence in can food of microbial toxins and microorganisms, dangerous for the health of consumer. In the cases when sterility is violated, can food to realization is shut out to the receipt of results their microbiological

\section{Results of Researches}

To study the effect of temperature as one of the most important parameters influencing the formation of histamine, samples of sardinella were stored for 10 months at a temperature of minus $18^{\circ} \mathrm{C}$. The authors studied the content 
of histamine in red and white muscles, as well as in the average sample, in accordance with the requirements of the normative document (Table 3 ).

In the work [8], the fact of histamine determination in 20 batches of mackerel is given. The fish was frozen at minus 35 - $28^{\circ} \mathrm{C}$ and stored at a temperature of $18-20^{\circ} \mathrm{C}$ for 4 months. The amount of histamine was fixed and remained practically unchanged. The author's data, presented in Table. 3 , confirm the fact of fixation of histamine within 4 months. Refining the experiment, the author examined the samples after 4 months of storage. The maximum histamine content was detected in frozen fish after 6 months of storage. After 8 months, the histamine content began to decrease and by the end of the tenth month, decreased. We are research the fact that some bacteria absorb histamine at low temperatures. In the middle of the experiment, the amount of histamine in the dark and light musculature practically leveled off. The level of histamine content in the light musculature is higher than in the dark and at the beginning of the experiment, and after 10 months of storage. Since the presence of internals in the abdominal cavity of the fish enhances the production of histamine, an assumption has arisen about the possible concentration of it in the tissues of the abdominal walls. The results of [8], obtained in the determination of histamine in undivided herring, showed that there is much more histamine in the tissues of the abdominal walls than in the tissues of the dorsal part. From what the authors of this article suggested that the histamine distribution indicated in Table 3 may arise due to untimely removal of the viscera from the sample after catch, which probably leads to an increase in histamine in the light muscles of the abdominal part of the fish.

The analysis of literature sources $[5,6,7,8,9,10]$ allows to reveal numerous factors responsible for the accumulation of histamine in fish canned goods. The domestic literature does not determine the effect of storage time, temperature and other factors on process of histamine formation. In connection with this, studies of the accumulation of histamine in canned fish are an important and urgent problem. The purpose of this paper is to quantitatively determine the mass fraction of histamine in fish and canned fish, depending on the shelf life, storage temperature, the type of liquid phase of the canned food and the $\mathrm{pH}$ level. The author also carried out a study of histamine changes after blanching fish defused. The initial value of the mass fraction of histamine in canned fish "Atlantic mackerel natural with the addition of oil" was $37 \mathrm{mg} / \mathrm{kg}$. The cans were thermostatic at temperatures of $20^{\circ} \mathrm{C}$ and $30^{\circ} \mathrm{C}$. After 4 months, a slight increase in histamine was observed at $30^{\circ} \mathrm{C}$ and no growth at $20^{\circ} \mathrm{C}$. After 7 months, the level of histamine content did not change. After 10 months, the maximum histamine content was recorded and was $50 \mathrm{mg} /$ $\mathrm{kg}$ at $20^{\circ} \mathrm{C}$ and $30^{\circ} \mathrm{C}$. After 12 months, the histamine content decreased to almost the original value and was $36 \mathrm{mg} / \mathrm{kg}$. At the same time, examining canned food "Sardinella natural with the addition of oil", the maximum growth of histamine was recorded after 7 months, 10 months later, the histamine content decreased to the initial value, and after 12 months to $14 \mathrm{mg} / \mathrm{kg}$. During the experiment, it was found that raising the temperature to $30^{\circ} \mathrm{C}$ does not lead to visible and significant changes. However, in the samples of canned products "Atlantic mackerel natural with the addition of butter" and "Sardinella natural with the addition of oil", a regularity was found: 10 months after the production of canned mackerel and 7 months after the production of canned sardine, an increase in the histamine content was observed; 12 months - a decrease in the level of histamine. In the course of the experiment it was possible to find out that at a temperature of $37^{\circ} \mathrm{C}$, histamine is significantly increased even after 1 month of thermosetting and at the end of the thermosetting for 12 months the amount of histamine increases in 2 times. In works $[9,10]$ attribute this fact to the fact that, as preserves are stored, renaturation of enzymes may take place, the degree of manifestation of which depends on the properties of the raw materials, the sterilization and storage of canned food. Carrying out experiments under conditions of artificial aging at a temperature of $37^{\circ} \mathrm{C}$, suggested that as the canned food is stored, enzyme renaturation can occur, the degree of activity of which depends also on the type of liquid phase.

Table 3. The level of histamine content in the frozen sardinella.

\begin{tabular}{|c|c|c|c|c|c|}
\hline \multirow{2}{*}{ Type of fish specimen in which histamine was determined } & \multicolumn{5}{|c|}{ Limits of histamine content, mg / kg } \\
\hline & 48 & 44 & 63 & 29 & 27 \\
\hline In light muscles & 48 & 44 & 63 & 29 & 27 \\
\hline In the dark muscles & 30 & 47 & 62 & 31 & 16 \\
\hline Average sample (combined) & 50 & 43 & 66 & 30 & 22 \\
\hline
\end{tabular}

According to the previously published data of [8], in fish in autolysis, after blanching, the content of histamine decreased by 1.25 times compared to fresh fish. Perhaps this is due to the transition of some part of histamine to the liquid part of the canned food. The author conducted an experiment to identify histamine in canned food from blanched and unblanched fish. Canned goods were made from one batch of frozen mackerel, both kinds of canned food were of the same manufacturing date. After the determination of histamine in both samples, it was found that in histories of blanched fish, the level of histamine is lower. Due to the fact that at the present time the canning is made from ice cream raw materials, the author found it necessary to conduct studies to determine the influence of the process of blanching the defrosted fish raw material on the change in the amount of histamine. Blanching by steam of sardinella-carcass was performed at a temperature of $100-105^{\circ} \mathrm{C}$ for 30 minutes. The mass fraction of histamine in sardinella before blanching was $265 \mathrm{mg} / \mathrm{kg}$, after blanching the histamine content dropped to $129 \mathrm{mg} / \mathrm{kg}$. The authors conducted an 
experiment to determine histamine in canned food "Atlantic fried mackerel in tomato sauce". It was found that the level of histamine in canned food in tomato sauce after storage for 7 months at a temperature of $37^{\circ} \mathrm{C}$ has halved. The present study clarifies the fact of histamine decrease in tomato sauce and the influence of the $\mathrm{pH}$ level on its change, expressed in the work [10]. In the work [8], the facts of the influence of the $\mathrm{pH}$ value on level of histamine. the experiment in [8] have shown that the intensity of histamine formation is clearly attenuated at value ph 5-5.4.

\section{Conclusions}

The studies are aimed at establishing the causes of the accumulation of histamine in fish raw materials and canned food in order to justify recommendations for the preliminary processing of fish raw materials, the application of certain technological production regimes and the establishment of the histamine remote control for fish raw materials, especially the fish family's mackerel, herring, anchovies, lawfare intended for the production of preserves. Tests of sardinella and mackerel frozen in Ukraine, confirmed the existence of the problem of histamine accumulation in fairly high limits during transportation and storage. The analysis of catch and transport conditions allows the authors to conclude that the producers of these products violate the correct sanitary and hygienic practices. In accordance with the obtained data on the accumulation of histamine in canned food from sardinella and mackerel, the authors propose to consider the question of reducing the norm of the mass fraction of histamine in raw materials for canning production. Further studies of the determination of histamine in canned food at the last storage period will contribute to establishing a critical limit for the level of histamine for fish raw materials.

The data obtained can be used to develop a quality and safety management system for the production of canned fish based on the HACCP principle for hazard analysis, to establish critical limits for control critical points for histamine accumulation, and to establish more stringent norms of mass fraction of histamine in fish raw materials, used for canning, in the relevant regulatory and technological documents of Ukraine.

\section{References}

[1] To the 57 Codex Alimentarius. Norms and rules for fish and fish products / Trans. with English. - Moscow: Publishing house "All World", 2007. -156 p.

[2] Commission Regulation (EC) No 2073/2005 of 15.11.2005 "On microbiological criteria for food products".

[3] Sanitary-epidemiological rules and standards "Hygienic requirements for food safety and nutritional value", SanPiN 2.3.2.1078-01.

[4] Medical and biological requirements and sanitary standards of food and foodstuffs quality, MBTiSN №5061-89.

[5] Safety and quality of fish and seafood / G. Allan Bremner (red.) - Per. with English. V. Shirokova; scientific. Ed. J. G. Bazarnova. - SPb.: The profession, 2009. - 512 p., Ill. Table. (Series: Scientific foundations and technologies).

[6] Rosier J. A screening method for the simultaneous determination of putrescine, cadaverine, histamine, spermidine and spermine in fish by means of HPLC of their 5dimethylaminonaphtaline-l-sylphonyl derivatives / J. Rosier, C. Peteghem // Z. Lebensm-Untersuch. und Forsch. - 1988. Vol. 186. - No. 1. - P. 25-28.

[7] Ritchie A. H. Advances in Fish Science and Technology / A. H. Ritchie, L M. Mackie. - Farnham Fishing (England), 1980. - P. 489-494.

[8] Kizevetter, I. V, "On the accumulation of histamine in the tissues of the body of the Pacific mackerel" / Kizevetter, I. V, and Nasedkina, EA, Izvestiya Pacific Scientific Research Institute of Fisheries and Oceanography. -Vladivostok, 1972. T.: 83.- P.27-34.

[9] Podsosna MA, Rodina TG The problem of histamine in fish products. - News of higher educational institutions. Food technology. 2004, No. 1, p. 30-32.

[10] Chaschina S. L Investigation of the level of histamine in canned fish in the course of storage / S. L Chashchina, L. T Serpunina // Actual problems of development of the biological resources of the World Ocean: materials of the international. Scientific-practical. Conf. - Vladivostok, 2010. - P. 54-58. 